\title{
PSII Activity as An Ecological Indicator for Assessing Impact from Variable Exposure at Community-Level
}

\author{
Tan C. Khun, Carolyn Oldham, and Louis Evans
}

\begin{abstract}
Protection of ecological health of aquatic ecosystems is a primary focus of water quality programs globally. Of special concern is the degradation impact from urban stormwater. Urban storm runoff is highly variable in both physical and chemical stressors, and can impact by changing the structure and physiology of ecological communities. We propose the use of photosystem II (PSII) activity of local periphyton communities for detecting impacts on the ecological health of aquatic ecosystems. This study evaluated the sensitivity of PSII response of periphyton communities to environmental stress in the field and stress (copper toxicity) simulated in the laboratory. The field study was done on natural periphyton communities at two sites in the Swan River estuary, Western Australia receiving urban stormwater discharge. Natural community at a non-receiving upstream site was used as the control. The laboratory study involved a chronic and an acute exposure to copper using periphyton community collected at the control upstream site. Both the laboratory and field studies indicated that PSII response was a sensitive indicator to the different exposures than the response in biomass, chlorophyll a content, or in-vivo chlorophyll fluorescence. Response in PSII also correlated strongly with the structural changes of the communities in total individuals $(\mathrm{N})$ and species number (S) (Pearson's coefficient 0.9 at sig $<0.01$ ). Communities pre-exposed to chronic copper, exhibited enhanced PSII activity that correlated positively with the increased community tolerance to copper toxicity. The PSII activity of communities receiving urban stormwater was indicative of the stormwater quality in that lower activity corresponded to poorer water quality. The results demonstrated that community PSII response to be sufficiently sensitive to environmental stress, including urban stormwater that is episodic and highly variable.
\end{abstract}

Index Terms-PSII quantum yield, periphyton community, ecological impact, variable exposure, urban stormwater.

\section{INTRODUCTION}

Urban storm runoff has a major impact on receiving aquatic ecosystems. Physical and chemical approaches for assessing runoff impacts have been found inadequate, and there is now recognition of the need for ecological approaches for more effective protection of the aquatic ecosystems [1], [2]. An ecological-based approach relies on our ability to define environmental impacts not only in terms of chemical and physical qualities, but also in terms of

Manuscript received December 8, 2012; revised February 19, 2013. This work was supported in part by the Australian Postgraduate Award.

C. K. Tan is with the Universiti Tunku Abdul Rahman, Faculty of Engineering and Green Technology, Malaysia (e-mail: tckhunr@utar.edu.my).

C. Oldham is with the University of Western Australia, Western Australia, Australia. (e-mail: carolyn.oldham@uwa.edu.au).

L. Evans was with Curtin University, Western Australia, Australia, is now retired. ecological health. One of the more serious challenges is in defining the impact of storm runoff, which is episodic and has multiple stressors. An appropriate indicator of ecological health for receiving aquatic ecosystems would be necessary. This indicator should identify risks associated with the exposure to single and multiple stressors that are also variable in composition. It should also detect ecological perturbations and must demonstrate a quantitative relationship with the stressor to allow prediction of potential impacts.

Ecosystem degradation may be defined by changes to biotic community structure or ecological processes [3]. Biological indices, currently used for impact assessment of community structure, are based mainly on taxonomic analysis [4]. Taxonomic data are multivariate which can be problematic for establishing cause-effect relationships and, consequently, for predicting impacts [5]. Furthermore, tests based on biological enumeration, though generally suited to quasi-steady state situations, may not be appropriate for evaluating impacts of short-term stress such as storm runoff [6]. On the other hand, functional measures of ecological processes, such as primary productivity, nutrient cycling, and energy flow, are typically univariate, and therefore can be explicitly modelled mathematically for prediction of impact. Since changes in physiological processes precede community structural changes [7], functional measures that integrate the collective activities of individuals in a community are more protective. Such functional measures are preferable to structural measures as indicators of environmental impacts, particularly where impacts are short-term and stress levels are not lethal, as in urban storm runoff. However, few functional parameters are currently in use, and they tend to be less sensitive than structural parameters [8]. In view of the potential advantages of functional measures, alternative analytical techniques need to be developed for detecting functional changes.

We propose photosystem II (PSII) activity as a functional measure for detecting degrading aquatic ecosystems. PSII yield measures the efficiency of the photosystem in harvesting solar energy for photosynthesis and is conveniently measured by pulse-amplitude modulated (PAM) fluorometry. As a performance indicator of primary productivity, PSII activity is ideal for detecting ecological impacts. The aim of this study is to evaluate the sensitivity of PSII response of periphyton community to variable exposure of copper and to urban stormwater discharge.

Periphyton communities are important to the productivity of aquatic systems. It is well documented that periphyton are good biological indicators of chemical and physical stress [9]. The periphyton community, as a highly diverse community in taxonomy and genetics, can provide an integrated source of 
information for impact studies in nearly every situation [10]. If the community response is predictable, it can provide an early warning of impact on the ecosystem. Copper is a common contaminant in urban storm runoff [11]. Although copper is an essential micronutrient to periphyton, it is toxic when in excess [12]. Excessive copper can inhibit algal photosynthesis and cause structural changes to periphyton communities, thereby degrading aquatic ecosystems [13], [14].

\section{MAterials AND Methods}

\section{A. Experimental Design}

This study was conducted in the laboratory and in the field. The communities of periphytic organisms used for both studies were collected from the Swan River estuary in Western Australia. The laboratory study comprised two exposure conditions to copper: a long-term chronic exposure, and a short-term acute exposure. The long-term exposure was for 21 days to low copper concentration, range $0.05-0.3 \mathrm{mg} / \mathrm{l}$ $\mathrm{Cu}$, buffered with ethylenediaminetetraacetic (EDTA). This concentration range was selected to include the ambient concentrations (0.0013-0.05 mg/l Cu [15]) along the stretch of the Swan River estuary being studied. The short-term exposure was for 24 hours, at higher concentration range of 0.16-4 mg/l Cu, without EDTA buffering. This concentration range includes the concentrations $(0.01-1.3 \mathrm{mg} / \mathrm{l} \mathrm{Cu},[16])$ found in the urban stormwater drains of interest.

\section{B. Culture Media}

Experimental periphyton were maintained in the laboratory using f/2 medium [17] that was modified by reducing the concentration of copper and zinc to $10 \%$ of the original recipe. Copper concentration was reduced to minimize effects from blank culture media. Zinc concentration was reduced to minimize possible co-tolerance effects [18]. The medium was prepared in $0.45 \mu \mathrm{m}$-filtered seawater (taken from the Indian Ocean), adjusted with deionised water to $10 \%$ salinity (mean salinity at the study site during wet season). For the stock periphyton and the long-term chronic copper exposure, the culture media contained $3.82 \mathrm{mM}$ EDTA (as the disodium salt $\mathrm{C}_{10} \mathrm{H}_{14} \mathrm{~N}_{2} \mathrm{O}_{8} \mathrm{Na}_{2} .2 \mathrm{H}_{2} \mathrm{O}$, AJAX analytical grade) to reduce the effective toxicity of copper [19].

\section{Stock Periphyton Culture}

For the laboratory study, a stock culture of estuarine periphyton, local to the Swan River estuary of Western Australia, was used as the inoculant for the test communities. The stock periphyton was cultured by randomly collecting 3 lots of 2-1 estuarine water (total 6 1) from the study site, and placing it in a 24-1 tank containing 12-1 culture medium (total 18 1). Incubation was for a month in a cycle of $12 \mathrm{~h}$ dark: $12 \mathrm{~h}$ light (3000 lux, $60 \mathrm{~W}$ OSRAM daylight fluorescent light tube) at $20{ }^{\circ} \mathrm{C}$. An immersed water-pump circulated the tank solution. Weekly, the tank solution was decanted as much as possible, and replaced by estuarine water (6 1, freshly sampled) and culture medium. After one month, accumulated periphyton on the internal surfaces of the tank were collected, homogenised, and then suspended in $300 \mathrm{ml}$ fresh culture medium. This stock culture was kept in the dark, at $4^{\circ} \mathrm{C}$.

\section{Copper Solutions}

Copper solutions for the laboratory study were prepared from a $100 \mathrm{mg} / \mathrm{l} \mathrm{Cu}$ stock aqueous solution $\left(\mathrm{CuSO}_{4} .5 \mathrm{H}_{2} \mathrm{O}\right.$, AJAX analytical grade, in deionised water) by dilution with the respective culture media.

\section{E. Field Exposure of Periphyton Communities to Urban Storm Water}

Periphyton communities were colonized on the Swan River estuary at three sites, about $2.5 \mathrm{~km}$ apart (Fig. 1). Two sites, S1 and S2, were receiving urban storm water from the Chapman Main Drain (MD) and Bayswater MD, respectively. The third site, S0 is the control site, upstream from the urban drains. These urban drains are known to be among the top five major polluters of the Swan-Canning Estuary of Western Australia [20].

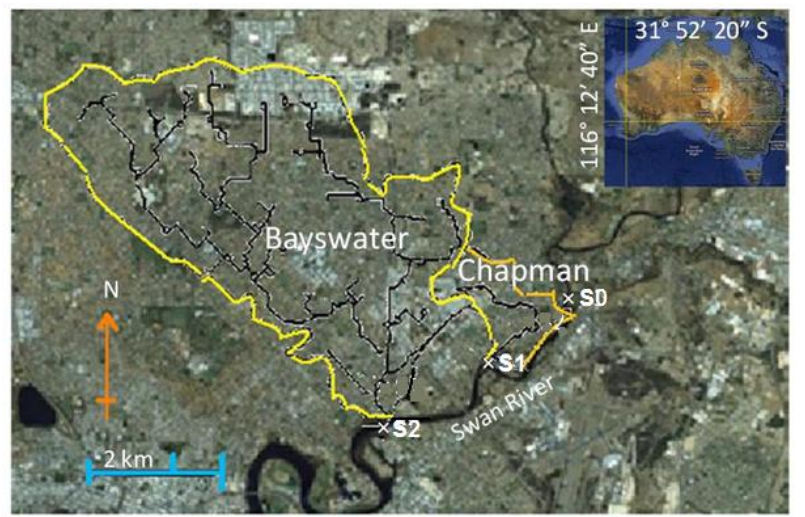

Fig. 1. Map showing the locations of the field sites of the Chapman MD (S1) and Bayswater MD (S2) downstream of the reference control site (S0) of the Swan River estuary, Western Australia; nset shows the geographic coordinates.

At each site, three lots of glass substratum collectors were placed $3 \mathrm{~m}$ apart across the river flow and $5 \mathrm{~m}$ from the northern bank. The collectors were held suspended at $1 \mathrm{~m}$ depth by a float and moored in position by weights (Fig.2). Each lot represented a replicate sampling. Each collector comprised 10 glass slides ( $75 \mathrm{~mm}$ x $25 \mathrm{~mm}$ x $1 \mathrm{~mm}$ ), held in a plastic rack.

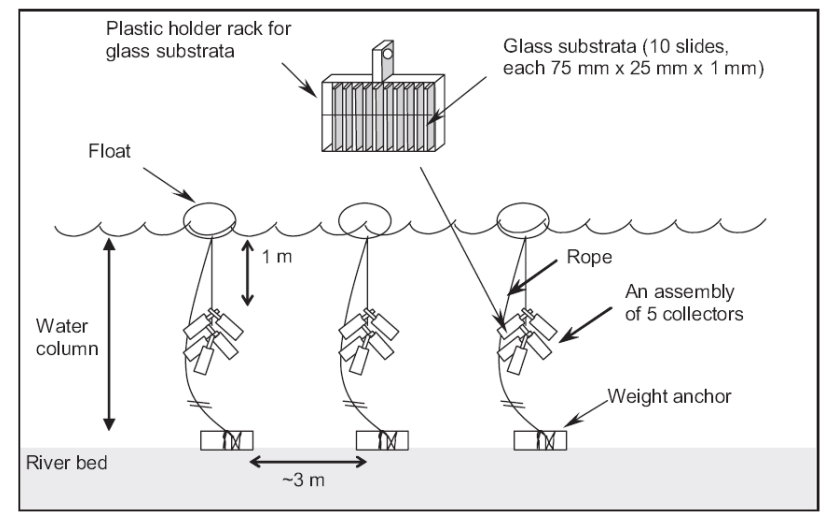

Fig. 2. Schematic assembly of glass substrata for collecting field periphyton communities in the river estuary.

The field colonization of the periphyton communities was conducted from 21 Sep-5 Oct 2001. Two series of storm 
event occurred during this period (Fig. 3). The developed periphyton communities were collected for analysis of biomass and PSII activity.
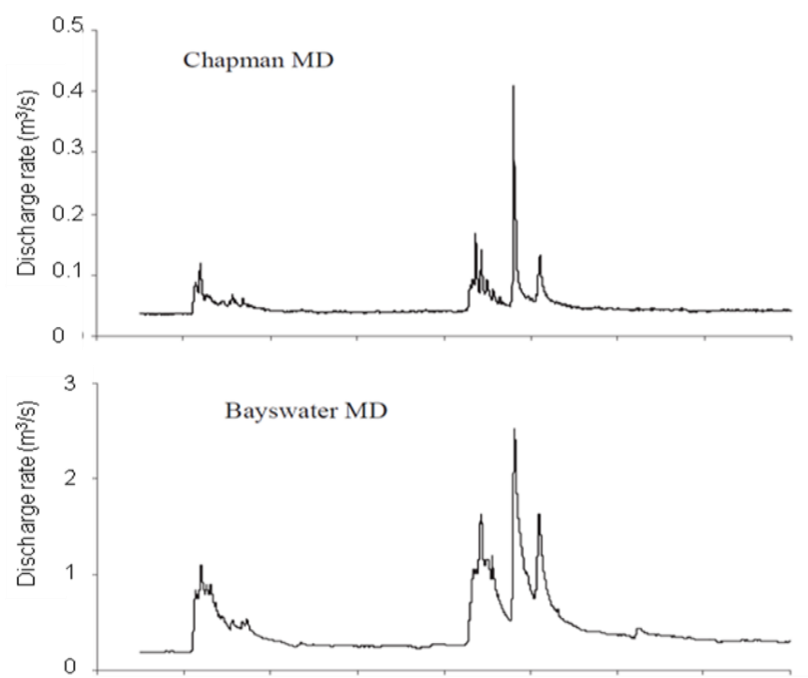

Fig. 3. Hydrographs of the Chapman MD and Bayswater MD indicating the occurrences of storm event during the field colonization period $21 \mathrm{Sep}-5$ Oct. 2001.

\section{F. Laboratory Study: Long-Term Chronic Copper Exposure}

An aliquot of $10 \mathrm{ml}$ periphyton stock culture was added, in triplicate, to 5-1 tanks of culture medium, spiked with copper to $0.05,0.1,0.15,0.2,0.25$, and $0.3 \mathrm{mg} / 1 \mathrm{Cu}$. A control culture medium was included, also in triplicate. The periphyton were allowed to develop on a rack of five glass plates (clear glass, $250 \mathrm{~mm} \times 75 \mathrm{~mm} \times 2 \mathrm{~mm}$ ), immersed in the tank solutions. The tank solutions were aerated. Incubation conditions were the same as for the stock culturing. Uniform light intensity was established in the incubation area to 1 standard error of $\pm 10 \%$ mean, using Digital Lux meter. The tanks were positioned randomly, with re-positioning weekly to offset variability in spatial conditions.

Exposure was for 21 days, which allowed good coverage of the glass plates by the periphyton (indicated by a trial experiment). The tank solutions were renewed weekly. A preliminary study indicated weekly renewal to be a suitable time period for maintaining the copper concentration within 1 standard error of $\pm 10 \%$ initial. The exposure concentrations were monitored weekly, i.e. at the start and end of the week. After the 21 days, the periphyton communities developed were collected, mixed in a tissue homogenizer, and made up to $50 \mathrm{ml}$ with the respective fresh culture media. The homogenized samples were analysed for PSII activity, in-vivo chlorophyll fluorescence, chlorophyll a content, biomass, and differences in community structure. The homogenized samples were also used for the study of short-term acute copper exposure.

\section{G. Laboratory Study: Short-Term Acute Copper Exposure}

For The short-term copper exposure was done using the communities pre-exposed to 0.1 and $0.3 \mathrm{mg} / \mathrm{l} \mathrm{Cu}$, plus the control community. The periphyton test samples were first rinsed and centrifuged three times with the short-term culture medium before maintaining them suspended in the short-term culture medium. The periphyton samples were then added to a series of $0.2,0.5,1,2,3,4$, and $5 \mathrm{mg} / \mathrm{l} \mathrm{Cu}$ in culture plates of $3 \mathrm{ml}$-wells, in a ratio of $0.5 \mathrm{ml}$ to $2 \mathrm{ml}$ respectively. This diluted the copper concentrations to $0.16,0.4,0.8,1.6,2.4$, 3.2 , and $4 \mathrm{mg} / \mathrm{l} \mathrm{Cu}$ in the test samples, respectively. A blank medium solution was included as the control. All tests were in triplicate.

The samples were incubated in light regime of 10-h light, 12-h dark and 2-h light, making a total of 24 hours. Other conditions were as for the long-term exposure. At the end the 24-h exposure, PSII activity was measured. Effect endpoints were determined from the response curve of PSII activity versus copper concentration of the short-term exposure. Effect endpoints $\mathrm{EC}_{5}$ and $\mathrm{EC}_{50}$ were determined by the ICp Method [21]. The periphyton samples were also analysed for community structural changes.

\section{H. Determination of Chlorophyll Fluorescence Parameters}

The parameters related to chlorophyll fluorescence to determine included PSII activity and in-vivo chlorophyll. PSII activity was determined as the effective yield under steady-light condition using a pulse-amplitude modulation (PAM) fluorometer (Walz Diving PAM). This PSII quantum yield was determined in low, non-photoinhibiting light intensity (mean photosynthetic photon flux density $=42.5 \pm 1$ standard deviation of 0.6 mol. $\mathrm{m}^{-2} \mathrm{~s}^{-1}$, Quantum Scalar Laboratory 2100 light sensor), at $20^{\circ} \mathrm{C}$. Aliquots of $2.5 \mathrm{ml}$ periphyton test samples, in triplicate, were conditioned in culture plates ( $3 \mathrm{ml}$ x 24 wells, flat-bottom, clear polystyrene, with cover, untreated, sterile) for at least one hour before measurement. Three measurements were taken at different, non-overlapping locations of the sample wells, giving $n=3$ discrete PSII quantum yield measurements per sample well. The arithmetic mean was reported.

In-vivo chlorophyll fluorescence (denoted by $\mathrm{F}_{0}$ ) was determined after adapting the test samples in the dark for one hour [20].

\section{Chlorophyll a Content Determination}

Chlorophyll a content was determined by spectrophotometric analysis on acetone extracts, following APHA Method 10200H [22]. Determination was in triplicate. However, this method was found not sufficiently sensitive for the short-term exposure where the amount of the exposed test samples was too low.

\section{J. Biomass Determination}

Community biomass was determined as ash-free dry weight according to APHA Method 10200 [22]. Briefly an aliquot of the test periphyton samples was filtered through glass-fibre filter (dia $22 \mathrm{~mm}$, Whatman) by vacuum-suction, rinsed with deionised water and drained for 5 minutes before transferring to a clean $10 \mathrm{ml}$ crucible, with lid. A blank run with the glass-filter and test sample medium (culture medium or deionised water) was included. The analysis was in triplicate.

\section{K. Copper Analysis}

Copper concentrations in test solutions for the long-term and short-term exposure studies were determined by flame 
atomic absorption spectrophotometry (Perkin Elmer AAnalyst 300 spectrophotometer) against standard copper solutions (Spectrosol@). Test samples were filtered through $0.45-\mu \mathrm{m}$ filters (dia $4 \mathrm{~cm}$, sterile, disposable, non-pyrogenic cartridge, Sartorious Minisart ${ }^{\circledR}$ NML) and preserved with a drop of nitric acid (AJAX concentrated $\mathrm{HNO}_{3}$, analytical grade). Measurements were taken after nitric acid digestion.

\section{Community Structure Analyses}

Community structure was analysed for total number of individuals $(N)$, total number of species $(S)$, species richness $(d)$, species evenness $(J)$, and the biodiversity indices of Shannon index $(H)$ and Simpson index $(1-\lambda)$. The parameters $N$ and $S$ were determined by direct enumeration. Parameters d and $\mathrm{S}$ were adjusted to allow for differing number of individuals. To facilitate easy visual examination, test samples were stained and fixed following Method 10200 Fc6 in APHA [22]. Briefly, this involved preserving in 1\% Lygol before staining with $1 \%$ Fuschin $(1 \mathrm{~g}$ in $100 \mathrm{ml}$ of $2 \%$ acetic acid), and dehydrating by rinsing in $50 \%, 90 \%$, and $100 \%$ propanol, successively, and lastly in xylene.

For the short-term acute copper exposure, communities were examined for signs of cell damage, and analysed for only presence or absence of species.

\section{Statistical Analysis}

Association between the community response measures and copper exposures was examined by correlation analysis (Pearson's). Test of significant differences was performed post analysis of variance (ANOVA), using the software package SPSS for Windows, Version 11.

Differences between communities were analysed by multivariate and from distribution curves using the Primer V5 program (PIMER-E Ltd). Here, the comparison of two or more communities is based on the extent to which they share particular characteristics. Most commonly used is the Bray-Curtis similarity coefficient [23]. The similarity coefficient facilitates subsequent analysis to discriminate between individual entities or groups using non-metric multidimensional scaling (MDS). The MDS presents the analytical outcomes on a 2-D or 3-D plot, where the differences or similarities between communities are indicated by their locations and distances apart. By ranking the differences or similarities in a non-metric order, the MDS plot can provide a simple yet compelling visual representation of the relative 'closeness' of the communities [24].

\section{RESULTS}

Measured concentration of the copper solutions for the laboratory study was within $\pm 5 \%$ of the nominal concentration. Weekly solutions of the long-term exposure were between $91 \%$ and $102 \%$ of the initial values. Hence, concentrations of the copper test solutions were taken to be the nominal concentrations, respectively.

\section{A. Field Community Responses to Urban Storm Discharge}

Response measures of the field communities are listed in Table I. Community biomass at the Bayswater MD was comparable to the reference site, but was lower at the Chapman MD. However, between community differences were not significant statistically (Mann-Whitney sig > 0.5). In contrast, PSII response was significantly lower for both the communities receiving urban storm discharge than for the reference community (Mann-Whitney sig < 0.001). The difference between the receiving communities was not statistically significant (Mann-Whitney sig > 0.5).

TABLE I: THE RESPONSE OF FIELD COMMUNITIES IN BIOMASS AND PSII ACTIVITY

\begin{tabular}{lccc}
\hline \hline Response Measure* & $\begin{array}{c}\text { Reference Site } \\
(\mathrm{S} 0)\end{array}$ & $\begin{array}{c}\text { Chapman MD } \\
(\mathrm{S} 1)\end{array}$ & $\begin{array}{c}\text { Bayswater } \\
\text { MD (S2) }\end{array}$ \\
\hline Biomass (mg) & $14 \pm 2$ & $10 \pm 2$ & $14 \pm 2$ \\
PSII quantum yield & $0.690 \pm 0.002$ & $0.670 \pm 0.003$ & $0.669 \pm 0.008$ \\
\hline \hline
\end{tabular}

*Values are mean $\pm 1 \mathrm{sd}, \mathrm{n}=3$

B. Community Responses to Laboratory Long-Term Chronic Copper Exposure

Community responses to the 21-d chronic copper exposure are presented in Table 2 and Fig. 4. There was a rich diversity of periphytic organisms, with at least 10 different forms observed. Total number of individuals $(N)$ was in the order of 103. Pennate diatoms dominated the communities, with the Nitzschia sp. constituting more than $80 \%$ of the community population. The Naviculoid sp. varied highly across the communities, from $2.5 \%$ to $16 \%$. Others included protozoa and picoorganisms. The protozoa identified were mainly Ciliates, Amoeba, and Vorticelli. Protozoa varied between $4.5 \%$ and $13 \%$. Overall, between the copper-exposed and control communities, there was no significant difference in any of the structural parameters (i.e. $N, S, d, J, H$, and $1-\lambda$ ).

TABLE II: RESPONSE IN COMMUNITY STRUCTURE TO LABORATORY LONG-TERM 21-D CHRONIC COPPER EXPOSURE

\begin{tabular}{lccccccc}
\hline \hline $\begin{array}{l}\text { Long-term } \\
\begin{array}{l}\text { Exposure } \\
(\mathrm{Cu} \text { mg/l) }\end{array}\end{array}$ & Control & 0.05 & 0.1 & 0.15 & 0.2 & 0.25 & 0.3 \\
\hline $\begin{array}{l}\text { Total individuals } \\
(N)\end{array}$ & 1640 & 2090 & 2540 & 2230 & 2670 & 2700 & 2650 \\
$\begin{array}{l}\text { Total species } \\
(S)\end{array}$ & 12 & 12 & 14 & 14 & 14 & 13 & 15 \\
$\begin{array}{l}\text { Species richness } \\
(d)\end{array}$ & 1.49 & 1.44 & 1.66 & 1.69 & 1.65 & 1.52 & 1.78 \\
$\begin{array}{l}\text { Species eveness } \\
(J)\end{array}$ & 0.32 & 0.36 & 0.39 & 0.41 & 0.36 & 0.35 & 0.3 \\
$\begin{array}{l}\text { Shannon index } \\
(H)\end{array}$ & 0.78 & 0.9 & 1.03 & 1.08 & 0.94 & 0.9 & 0.8 \\
$\begin{array}{l}\text { Simpson index } \\
(1-\lambda)\end{array}$ & 0.32 & 0.38 & 0.48 & 0.46 & 0.43 & 0.39 & 0.3 \\
\hline \hline
\end{tabular}

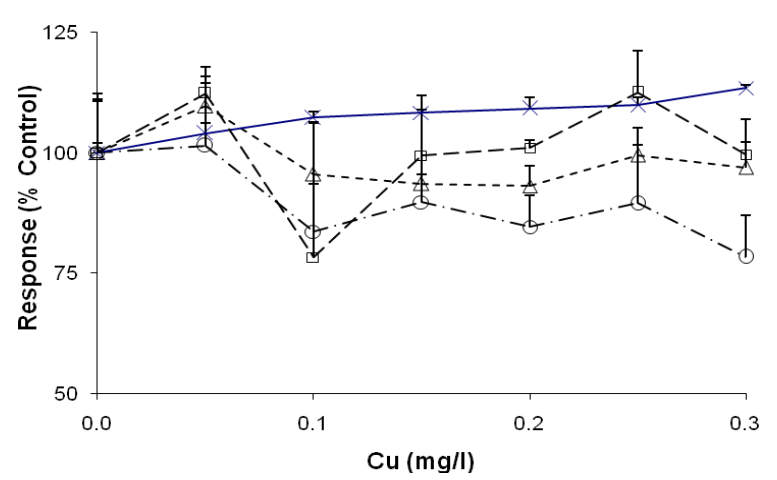

Fig. 4. Community response to long-term 21-d chronic exposure of 0.05, 0.1, $0.15,0.2,0.25$, and $0.3 \mathrm{Cu} \mathrm{mg} / \mathrm{l}$ in PSII activity $(\times)$, in-vivo chlorophyll fluorescence $(\mathrm{O})$, biomass $(\Delta)$, and chlorophyll a content $(\square)$; response measures are the mean $(n=3)$ as $\%$ of the control community, error bar $=1$ sd. 
The long-term chronic exposure to copper has the effect of enhancing PSII activity of the communities (Fig. 4). The PSII activity correlated strongly and positively with the concentration of the long-term copper exposure (Pearson's coefficient $>0.85$, sig 0.01). Response in in-vivo chlorophyll fluorescence $\left(\mathrm{F}_{0}\right)$ also correlated strongly and positively but with a lower correlation coefficient (Pearson's $>0.79$ ) than PSII response. The other responses in biomass and chlorophyll $a$ content were only weakly correlated with concentration of the copper exposure (Pearson's coefficient $<$ $0.50)$.

There was also a strong correlation between PSII activity and the community structure of $N$ and $S$ (Pearson's coefficients of 0.9 at sig. $<0.01$ ).

\section{Community Responses to Laboratory Short-Term Acute Copper Exposure}

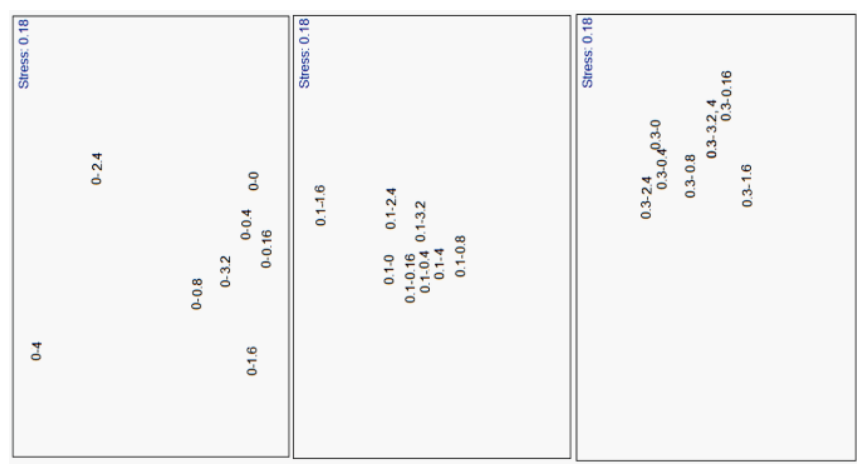

Fig. 5. MDS plots showing differences between communities in structure after 24-h acute copper exposure, where the distances apart corresponds to the community differences; the points ' $\mathrm{x}-\mathrm{y}$ ', where $\mathrm{x}$ denotes that the concentration in $\mathrm{Cu} \mathrm{mg} / \mathrm{l}$ of the 21-d exposure and y denotes that of the 24-h exposure, ' 0 ' denotes the control medium..

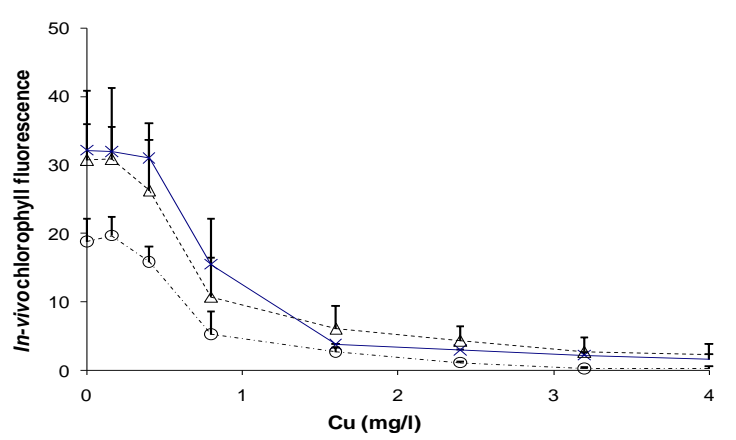

Fig. 6. In-vivo chlorophyll fluorescence response curves to short-term 24-h acute copper exposure for communities pre-exposed to $0.1 \mathrm{Cu} \mathrm{mg/l}(\Delta)$ and $0.3 \mathrm{Cu} \mathrm{mg} / \mathrm{l}(\mathrm{O})$ and the control medium $(\times)$; error bar $=1 \mathrm{sd}, \mathrm{n}=3$.

High copper concentration impaired the periphyton communities by causing cellular damage in organisms. The Nitzschia sp. appeared bloated with disintegrated or fragmented cell structure. The Naviculoid sp. also suffered from cellular disintegration even though they retained their form of siliceous cell casing. On the other hand, short-form pennate diatoms inhabiting in tubes tended to stay intact in high exposure concentration. Cellular damage, observed as disintegrated cell contents or fragmented cell structures, was more apparent with increased concentration of the short-term exposure. Overall, the control community responded to the 24-h acute copper exposure in the laboratory with greater changes in structure than the pre-exposed communities. This is indicated by the greater distances apart in the MDS plot for the control community compared to the communities pre-exposed to $0.1 \mathrm{mg} / \mathrm{l} \mathrm{Cu}$ and $0.3 \mathrm{mg} / \mathrm{l} \mathrm{Cu}$ (Fig. 5). Between the pre-exposed communities, the points are nested closer for the higher pre-exposure copper concentration.

Community responses in both PSII activity and in-vivo chlorophyll fluorescence varied with the exposure concentration of copper (Fig. 6 and Fig. 7, respectively). In general, both the responses decreased with increased exposure concentration. Both the pre-exposed communities have higher $\mathrm{EC}_{5}$ and $\mathrm{EC}_{50}$ than the control community (Table III). The community pre-exposed to $0.3 \mathrm{Cu} \mathrm{mg} / \mathrm{l}$ exhibited stimulatory PSII response at low copper concentration.

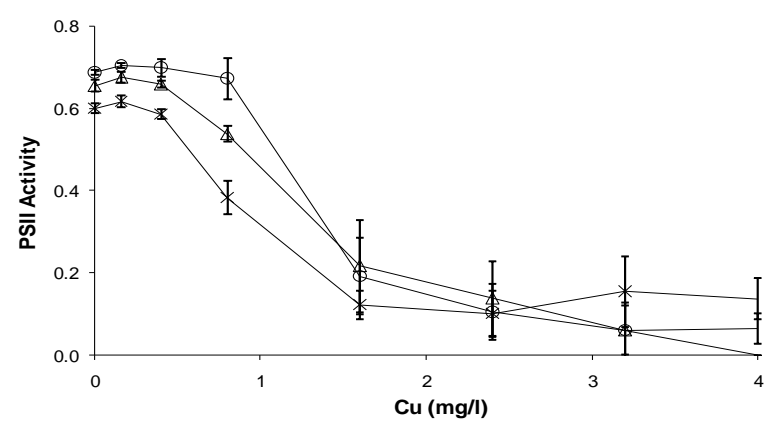

Fig. 7. PSII response curves to short-term 24-h acute copper exposure for communities pre-exposed to $0.1 \mathrm{Cu} \mathrm{mg/l}(\Delta), 0.3 \mathrm{Cu} \mathrm{mg/l}(\mathrm{O})$, and the control medium $(\times)$; error bar $=1 \mathrm{sd}, \mathrm{n}=3$.

TABLE III: EFFECT CONCENTRATIIONS FROM THE COMMUNITY PSII RESPONSE CURVES OF SHORT-TERM ACUTE COPPER EXPOSURE

\begin{tabular}{lccc}
\hline \hline $\begin{array}{l}\text { Pre-exposure } \\
(\mathrm{Cu} \mathrm{mg} / \mathrm{l})\end{array}$ & $\begin{array}{c}\mathrm{EC}_{5} \\
(\mathrm{Cu} \mathrm{mg} / \mathrm{l})\end{array}$ & $\begin{array}{c}\mathrm{EC}_{50} \\
(\mathrm{Cu} \mathrm{mg} / \mathrm{l})\end{array}$ & $\begin{array}{c}\text { Stimulatory } \\
\text { Response }\end{array}$ \\
\hline Control medium & 0.42 & 1.06 & None \\
0.1 & 0.50 & 1.31 & None \\
0.3 & 0.79 & 1.21 & Yes \\
\hline \hline
\end{tabular}

\section{Discussion}

The laboratory study indicated two effects of copper: an enhancing effect and a suppressing effect. High concentration of copper suppressed PSII activity and, hence photosynthetic efficiency of the estuarine periphyton communities. This effect was accompanied by cellular damage. On the other hand, low concentration stimulated the activity to enhance photosynthetic efficiency. Pre-exposure to copper affected the community responses to subsequent acute exposure, from which is inferred that the long-term exposure promoted the development of periphyton communities that were more efficient photosynthetically and also more tolerant to copper.

The concomitant increase in photosynthetic efficiency and tolerance suggested that the tolerant periphytic organisms were more efficient in photosynthesis than the sensitive periphytic organisms. We believe that the community changes are necessary to maintain normal functioning of the communities [8]. Different classes of algae can be different in photosynthetic efficiency due to variation in the structural organization of their photosynthesis apparatus [25]. The changes observed in the short-term experiment can be attributed to individual organism responses, whereas the changes in the long-term experiment were in addition due to interactions within community. Rapid changes can be 
brought about by detective responses of certain organisms in the community that are reactive to the stressor, i.e. copper in this case. Alternatively, individuals that are very sensitive to copper can respond aberrantly resulting in direct or indirect impairment to the PSII system, or in their total removal [26]. On the other hand, certain organisms in the community can be adaptive by tolerating the stress that is temporary but not extended (i.e. within the exposure duration of $24 \mathrm{~h}$ ). This would result in no apparent changes. Changes over long term involving turnover of several generations, may include genetic adaptation, physiological acclimation, or removal of sensitive species. All these would imply a corresponding change in the community structure, which was indicated by the strong correlationship between the community PSII activity and structure in total number of individuals $(N)$ and species number $(S)$.

Studies by Gustavson and Wangberg [18] have indicated that copper can exert a selective pressure on aquatic micro-organisms to favour more tolerant species. The concentration-PSII yield curves describe the community tolerance distribution [26], and the differences between the short-term response curves reflect the changes brought about by the long-term pre-exposure to copper. Community tolerance is important in ecological risk management, especially for low-level contamination such as urban storm runoff. Protection of a particular biotic community from impact by a particular contaminant invariably means ensuring that the contaminant concentration in the environment does not exceed the community tolerance limit.

The long-term and short-term response curves of the periphyton communities both indicated that the community PSII response was dependent on both the exposure duration and concentration of the stressor copper. Variance analysis demonstrates that the response measure in PSII quantum yield was sufficiently sensitive to detect treatment differences in the short-term exposure as well as in the long-term exposure. Response in PSII correlated strongly to the exposure concentration of copper in the long-term treatment. The PSII response of the field communities also was indicative of the stress from the urban stormwater discharge that corresponded to the water quality. In comparison, the response measure of in-vivo chlorophyll fluorescence, biomass or chlorophyll $a$ content was not as indicative.

PSII quantum yield measures a rapid process of electron transport, of a time scale of milliseconds. Biomass and chlorophyll $a$ content, however, measure the slower process of growth on a time-scale of days and, therefore, are expected to respond more slowly than PSII activity. In-vivo chlorophyll fluorescence is a compensatory process in the regulation of excitation energy for photosynthesis and reacts to the same electron transport process that PSII quantum yield measures. This may explain the closeness of their correlation coefficients.

PSII yield has the advantage of being a general effect measure, allowing a wider applicability to any photosynthesizing biota, and is therefore not limited to periphyton assemblages only. However, being a universal response, PSII response is not specific to a particular stressor, or a class of stressors, but to most general stressors. Hence it does not indicate solely the effects of copper. As such, PSII response may not be able to identify the specific stressor. However, environmental impact is more likely to be a complex mixture of stressors, such as in the case of urban storm runoff. In providing a direct measure of physiological response of the periphyton community to environmental stress, PSII activity would be desirable when the concern is the ecological health of the ecosystem rather than a need to identify the stressors. Moreover, the effect measured will be a resultant impact, even though the measure would be indicative rather than absolute. According to the concept of pollutant-induced community tolerance (PICT) [27], increased community tolerance to a stressor, e.g. copper as in this study, relative to a reference site may be used as evidence of impact from that stressor. Perhaps, this may compensate for the limitation of PSII yield being a universal effect measure after all.

There is also the added advantage of being correlated to community structure. As assessment of community structure is typically multivariate, establishing the cause-effect relationship for predicting ecological impact can be problematic. Their correlation can facilitate the use of the PSII response measure, which is univariate, for establishing causal-effect and for predicting impacts. There is this very recent Chemotaxonomy technique based on pigment profiling for community structure [28; 29], but it is destructive whereas determination of PS activity is not. Combined with the analytical features of PAM fluorometry as a rapid and non-intrusive technique, there is potential for real-time, in-situ field measurements of PSII activity for assessing ecological impacts at the community level.

\section{CONCLUSION}

Our findings demonstrated PSII quantum yield to be an effective indicator of ecological impacts on an estuarine periphyton community. Community response in PSII was dependent on the duration and concentration of copper exposure. The PSII response measure correlated strongly with the community structure. It has the added advantage of being a universal response measure of photosynthetic efficiency that is of ecological significance.

\section{ACKNOWLEDGMENT}

The authors thank the Botany Department of the University of Western Australia for loan of the Walz Diving PAM. C.K. Tan is grateful to L. Evans of Curtin University, Western Australia, for organising the research scholarship.

\section{REFERENCES}

[1] J. R. Karr, "Defining and assessing ecological integrity: Beyond water quality," Environ Toxicol Chem, vol. 12, pp. 1521-1531, 1993.

[2] B. D. Haskell, G. G. Norton, and R. Constanza, "What is ecosystem health and why should we worry about it?" in Ecosystem Health: New Goals for Environmental Management, R. Constanza, G. G. Norton, B. D. Haskell, Eds., Washington: Island Press, 1992, pp. 1-18.

[3] C. Richards, "Integrated watershed analysis and study design," in Methods to Assess the Effects of Chemicals on Ecosystems, R. A. Linhurst, P. Bourdeau, R. G. Tardiff, Eds., Chichester: John Wiley \& Sons, 1995, pp. 263-297.

[4] C. O. Yoder and E. T. Rakin, "Biological criteria for water resource management," in Measures of Environmental Performance and 
Ecosystem Condition, P. C. Schulze, Ed., Washington: National Academy Press, 1999, pp. 227-259.

[5] M. T. Barbour, J. Gerritsen, B. D. Snyder, and J. B. Stribling, Rapid bioassessment protocols for use in wadeable streams and rivers: Periphyton, benthic macroinvertebrates and fish, Washington: US Environmental Protection Agency, 1999.

[6] M. Yasuno and B. A. Whitton, Biological Monitoring of Environmental Pollution, Tokyo: Tokai University Press, 1988.

[7] J. M. Culp, R. B. Lowell, and K. J. Cash, "Integrating mesocosm experiments with field and laboratory studies to generate weight-of-evidence risk assessments for large rivers," Environ Toxicol Chem, vol. 19, pp. 1167-1173, 2000.

[8] J. R. Pratt and J. Cairns, Jr., "Ecotoxicology and the redundancy problem: Understanding effects on community structure and function," in Ecotoxicology: A Hierarchical Treatment, M. C. Newman, C. H. Jagoe, Eds., Roca Baton: Lewis Publishers, 1996, pp. 347-370.

[9] R. L. Lowe and Y. Y. Pan, "Benthic algal communities as biological monitors," in Algal Ecology: Freshwater Benthic Ecosystems, R. J. Stevenson, M. L. Bothwell, R. L. Lowe, Eds., San Diego: Academic Press, 1996, pp. 705-739.

[10] J. H. Rodgers Jr., K. L. Dickson, and J. Cairns Jr., "A review and analysis of some methods used to measure functional aspects of periphyton," in Methods and Measurements of Periphyton Communities: A Review, R. L. Weitzel, Ed., Philadelphia: American Society for Testing and Materials, 1979, pp. 142-167.

[11] USEPA, Results of the nationwide urban runoff program, Washington: US Environmental Protection Agency, vol. 1, Final Report PB 84-185552, Dec. 1983

[12] B. E. Sample, G. W. Suter II, M. B. Sheaffer, D. S. Jones, and R. A. Efroymson, Ecotoxicological profiles for selected metals and other inorganic chemicals, Oak Ridge: US Department of Energy, 1997, pp. $1-25$.

[13] K. Knauber, R. Behra, and L. Siggi, "Effects of free $\mathrm{Cu}^{2+}$ and $\mathrm{Zn}^{2+}$ ions on growth and metal accumulation in freshwater algae," Environ Toxicol Chem, vol. 16, pp. 220-229, 1997.

[14] C. Barranguet and J. Kromkamp, "Estimating primary production rates from photosynthetic electron transport in estuarine microphytobenthos," Mar Ecol Prog Ser, vol. 204, pp. 39-52, 2000.

[15] DOEWA, Assessment of water, sediment and fish quality in the Bayswater drains and adjacent Swan River, Western Australia: Department of Environment, April/May 2003.

[16] C. K. Tan, "Ecotoxicological Study of Urban Runoff," PhD Thesis, The University of Western Australia, 2006.

[17] R. R. L. Guillard, "Culture of phytoplankton for feeding marine invertebrates," in Culture of Marine Invertebrate Animals, W. L. Smith, M. H. Chanley, Eds., New York: Plenum Press, 1975, pp. 29-60.

[18] K. Gustavson and S.-A. Wangberg, "Tolerance induction and succession in microalgal communities exposed to copper and atrazine," Aquat Toxicol, vol. 32, pp. 283-302, 1995.

[19] N. Franklin, J. Stauber, S. Markich, and R. R. Lim, A new tropical algal test to assess the toxicity of metals in freshwaters, Darwin: The supervising scientist, Environment Australia, 1998.
[20] R. Henderson and B. Jarvis, Urban drainage water pollution assessment study, Perth: Water Authority Report SSB 1, 1995

[21] T. J. Norberg-King, A linear interpolation method for sublethal toxicity: The inhibition concentration (ICp) approach (Version 2.0), Duluth: US Environmental Protection Agency, National Effluent Toxicity Assessment Center, Technical Report 03-93, 1993.

[22] Standard Methods for the Examination of Water and Wastewater, 20th ed. American Public Health Association, American Water Works Association, and Water Environment Federation, Washington, DC, USA, 1998

[23] J. R. Bray and J. T. Curtis, "An ordination of the upland forest communities of southern Wisconsin," Ecological Monographs, vol. 27 pp. 325-349, 1957

[24] K. R. Clarke and R. M. Warwick, Change in Marine Communities: An approach to Statistical Analysis and Interpretation, PRIMER-E Ltd, Plymouth, UK, 2001

[25] A. Cunningham, G. Levavasseur, M. Estrada, D. Hanelt, and C. Wilhelm, "Technical discussion III: Fluorescence measurements," in Underwater Light and Algal Photobiology, F. L. Figueroa, C. Jimenez, J. L. Perez-Llorens, F. X. Neil, Eds., Barcelona: International Centre for Coastal Resources Research, 1996, Scientia Mariana, vol. 60 Supl 1, pp. 301-302.

[26] V. E. Forbes and T. L. Forbes, Ecotoxicology: In Theory and in Practice, London: Chapman and Hill, 1994

[27] H. Blanck, S.-A. Wangberg, and S. Molander, "Pollution-induced community tolerance: A new ecotoxicological tool," in Functional Testing of Aquatic Biota for Estimating Hazards of Chemicals, J. Cairns Jr, J. R. Pratt, Eds., Philadelphia: American Society for Testing and Materials, 1988, STP 988, pp. 219-230.

[28] T. Porsbring, A. Arrhenius, T. Backhaus, M. Kuylenstierna, M Scholze, and H. Blanck, "The SWIFT periphyton test for high-capacity assessments of toxicant effects on microalgal community development," Journal of Experimental Marine Biology and Ecology, vol. 349, pp. 299-312, 2007

[29] R. A. Devilla, M. T. Brown, M. Donkin, and J. W. Readman, "The effects of a PSII inhibitor on phytoplankton community structure as assessed by HPLC pigment analyses, microscopy and flow cytometry," Aquatic Toxicology, vol. 71, pp. 25-38, 2005.

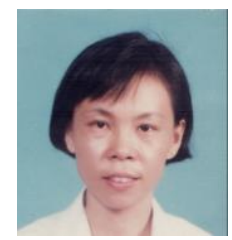

Tan C. Khun received her Ph.D. degree in Environmental Engineering from the University of Western Australia. Research area of interest is in sustainable management of environmental resources. Current research activities focused mainly on resource management, especially biowaste for up-cycling and sustainability. Also involved in related community-based projects that include sustainable settlement of indigenous communities of Malaysia, sustainable management of solid waste in New Villages of Malaysia, and River-care Programme. Currently a member of the International Solid Waste Association, Technological Association of Malaysia, and Asia Pacific Chemical Biological and Environmental Engineering Society. 